\title{
Investigation Progressive Collapse Behaviour of Double Layer Barrel Vault Space Structures
}

\author{
Mahdi Darvish Hashemi, Hadi Zarrintala \\ Department of Civil Engineering, Bonab Branch, Islamic Azad University, Bonab, Iran \\ Email: $\underline{m}$ d hashemi@yahoo.com, h.zartala@hotmail.com
}

Received 1 August 2015; accepted 23 October 2015; published 30 October 2015

\begin{abstract}
Space double-layer grids are structures that are vulnerable facing progressive collapse phenomenon. So some methods should be studied for space double-layer grids that their collapse behaviors change from a brittle one into a soft and ductile. Within this study, than of these structures progressive collapse behavior has been studied. This study answers this question that to which members early to take collapse of double-layer space barrel vaults grids. This research can be identified with the critical members of the progressive failure and overall structural damage avoided.
\end{abstract}

Keywords

Barrel Vault, Progressive, Buckling, Collapse, Ductility, Space Structures

\section{Introduction}

The main goal of this paper is investigation progressive collapse behavior of compression member buckling in double-layer space barrel vaults grids which consists of 12 model of double-layer space barrel vaults. These models have different condition supports, structure depth, structure plan geometrical form and geometrical imperfection. During two recent decades, several methods have been developed for controlling and study collapse behavior in of space trusses.

\section{Behavior Properties of Double-Layer Space Grids}

Double-layer space grids are of high redundancy and in general, 15 to 20 percent of their members are extra [1]. Whit these members' omit, structure will be stable statically. So it can be imagined that double-layer space grids have a very high safety against collapsing danger and can resist whit omitting of some of its members. But at these structure compression member buckling, tensile member yield, joint unstablility, member unsuitable joining and geometrical imperfection exist.

That leads to section collapse if the structure cannot enable this section local collapse. Collapse will remain partially in structure and won't convey to other parts. Otherwise collapse doesn't remain partial and extension 
the whole structure and finally leads to complete collapse of structure which is called progressive collapse' chain mechanism [2].

We can list some of the most important characteristic of doule-layer space grids as follow:

- The complete behaviour of doule-layer space grids structure depends on factors like geometrical characteristic and structural system instruments, members' cross-section area, joints type and their implementation method.

- One of the most important effective factors on structure collapse hehaviour is existing nonlinear geometrical factor and material nonlinear factors in practice. For space double-layer grids, the effect of material nonlinear is more important than geometric nonlinearity.

- In double-layer space grids, the compression member behaviour is one of the most important effective factors on their collapse behaviour the compression member behaviour, is from three important parameters of slenderness ratio, material yield stress, and member imperfection rate and through these it can be changed from very brittle mode to very soft state [3]. When a compression member from double-layer space grids buckles, it's load-carrying capacity has decreased and extension it's load to neighbouring member which depends on post-buckling behaviour of compression member. Considering post-buckling behaviour of compression member in collapse analysis of double-layer space grids, proves that collapse behaviour of these structures will be in three forms of total structure collapse, local collapse with dynamiic snap-through and local [3].

\section{Analysis of Collapse Behaviour in Double-Layer Space Barrel Vaults Grids}

At this study, there are 12 models of double-layer space barrel vaults grids designed which are studied at three conditions of supports with different configuration in the forms of corner-supported, edge-supported and edge vertical-arch-supported with two considered of $\mathrm{H} / \mathrm{S}=0.15, \mathrm{H} / \mathrm{S}=0.30$ (that $\mathrm{H}$ is effective height and $\mathrm{S}$ is effective span length) and ratio of span to depth 20 has been studied in all models which 3 models of these grids have been shown in Figure 1.

At studying of these models, design is based on AISC, then with analysis of every member of models members load-displacement behavior derived and after that with inserting every member behavior in models and with non-linear statical analysis of models by Finite Element Method by LUSAS software, load behaviour determines load-displacement behaviour in structure and critical members.

At this study, double-layer space barrel vaults grids members consist of circular tube Cross-sections. Grids have four different member length (according to Table 1) with the equal cross-section area in every model for top layers, bottom layers and web layers. Also, Yield stress is considered 3600, Youngs modulus is, poissons ratio 0.3 and members imperfection for double-layer space barrel vaults grids. Loading under dead load and live load has been done relatively with 50 and 200, the properties of consider models with different supports have been done in taple (1). At this table on first column the model name, $\mathrm{G}$ is symbol of grid, $\mathrm{C}$ is symbol of cornersupport, $\mathrm{E}$ is symbol of edge-Support and $\mathrm{L}$ is symbol of edge vertical-arch-supported, the first indice is showing grids in the length of vertical-arch and second indice shows the H/S ratio.

For doing collapse analysis on double-layer space grids, first structure members behavior should be determined. At this study, members axis load-displacement behavior in tension in the form of complete elastic-plastic has been taken into consideration. For determination of members axis load-displacement behavior in compressive, Finite Element Method has been used.

For studying of collapse behavior and collapse mecunism type in double-layer space barrel vaults grids, statical non-linear analysis has been done on these models. Both geometric nonlinearity and material nonlinearity factor to be considered through these analyses. The solution of equilibrium nonlinear equations is done by arclength method. Load-vertical displacement curve central joint of studied models which have been derived by statical analysis and the order and location of collapsed members have been shown in Figure 2.

\section{Conclusions}

1) In double-layer space barrel vaults grids, the change of corner supports into edge-supports and edge vertical-arch-supported leads to heavy structural weight loss and stiffness increase.

2) At models with corner supports, collapse starts with side members and with load carrying continuing and following structure equilibrium path it is extension toward internal members. At models with edge-supports, 
Table 1. Characteristics consider models with different supports.

\begin{tabular}{|c|c|c|c|c|c|c|c|c|c|c|}
\hline \multirow{2}{*}{$\begin{array}{l}\text { Model } \\
\text { Name }\end{array}$} & \multirow{2}{*}{$\begin{array}{c}\begin{array}{c}\text { Structure } \\
\text { Dimension } \\
(\mathrm{m})\end{array} \\
12 * 12\end{array}$} & \multirow{2}{*}{$\begin{array}{c}\begin{array}{c}\text { CHS } \\
(\mathrm{mm})\end{array} \\
57 * 2.9\end{array}$} & \multicolumn{2}{|c|}{$\begin{array}{l}\text { TOP Members } \\
\text { Slenderness and } \\
\text { Length }(\mathrm{m})\end{array}$} & \multicolumn{2}{|c|}{$\begin{array}{l}\text { BOT Members } \\
\text { Slenderness and } \\
\text { Length }(\mathrm{m})\end{array}$} & \multicolumn{2}{|c|}{$\begin{array}{l}\text { Length Members } \\
\text { Slenderness and } \\
\text { Length }(\mathrm{m})\end{array}$} & \multicolumn{2}{|c|}{$\begin{array}{c}\text { Web Members } \\
\text { Slenderness and } \\
\text { Length }(\mathrm{m})\end{array}$} \\
\hline & & & $\lambda=64$ & $\mathrm{~L}=1.22$ & $\lambda=60$ & $\mathrm{~L}=1.15$ & $\lambda=63$ & $\mathrm{~L}=1.20$ & $\lambda=54$ & $\mathrm{~L}=1.0$ \\
\hline $\mathrm{GC}_{12-0.30}$ & $12 * 12$ & $51 * 4$ & $\lambda=87$ & $\mathrm{~L}=1.45$ & $\lambda=80$ & $\mathrm{~L}=1.33$ & $\lambda=72$ & $\mathrm{~L}=1.20$ & $\lambda=67$ & $\mathrm{~L}=1.11$ \\
\hline $\mathbf{G C}_{18-0.15}$ & $12 * 18$ & $60.3 * 4.5$ & $\lambda=62$ & $\mathrm{~L}=1.22$ & $\lambda=58$ & $\mathrm{~L}=1.15$ & $\lambda=61$ & $\mathrm{~L}=1.20$ & $\lambda=53$ & $\mathrm{~L}=1.22$ \\
\hline $\mathrm{GC}_{18-0.30}$ & $12 * 18$ & $57 * 4.5$ & $\lambda=78$ & $\mathrm{~L}=1.45$ & $\lambda=71$ & $\mathrm{~L}=1.33$ & $\lambda=64$ & $\mathrm{~L}=1.20$ & $\lambda=60$ & $\mathrm{~L}=1.1$ \\
\hline $\mathbf{G E}_{12-0.15}$ & $12 * 12$ & $33.7 * 2.6$ & $\lambda=111$ & $\mathrm{~L}=1.22$ & $\lambda=104$ & $\mathrm{~L}=1.15$ & $\lambda=109$ & $\mathrm{~L}=1.20$ & $\lambda=94$ & $\mathrm{~L}=1.22$ \\
\hline $\mathrm{GE}_{12-0.30}$ & $12 * 12$ & $33.7 * 2.6$ & $\lambda=131$ & $\mathrm{~L}=1.45$ & $\lambda=121$ & $\mathrm{~L}=1.33$ & $\lambda=109$ & $\mathrm{~L}=1.20$ & $\lambda=101$ & $\mathrm{~L}=1.1$ \\
\hline $\mathrm{GE}_{18-0.15}$ & $12 * 18$ & $33.7 * 2.6$ & $\lambda=111$ & $\mathrm{~L}=1.22$ & $\lambda=104$ & $\mathrm{~L}=1.15$ & $\lambda=109$ & $\mathrm{~L}=1.20$ & $\lambda=94$ & $\mathrm{~L}=1.22$ \\
\hline $\mathrm{GE}_{18-0,30}$ & $12 * 18$ & $33.7 * 2.6$ & $\lambda=131$ & $\mathrm{~L}=1.45$ & $\lambda=121$ & $\mathrm{~L}=1.33$ & $\lambda=109$ & $\mathrm{~L}=1.20$ & $\lambda=10$ & $\mathrm{~L}=1.1$ \\
\hline $\mathrm{GL}_{12-0.15}$ & $12 * 12$ & $33.7 * 2.6$ & $\lambda=111$ & $\mathrm{~L}=1.22$ & $\lambda=104$ & $\mathrm{~L}=1.15$ & $\lambda=109$ & $\mathrm{~L}=1.20$ & $\lambda=94$ & $\mathrm{~L}=1.22$ \\
\hline $\mathrm{GL}_{12-0.30}$ & $12 * 12$ & $33.7 * 2.6$ & $\lambda=134$ & $\mathrm{~L}=1.45$ & $\lambda=123$ & $\mathrm{~L}=1.33$ & $\lambda=111$ & $\mathrm{~L}=1.20$ & $\lambda=10$ & $\mathrm{~L}=1.11$ \\
\hline $\mathrm{GL}_{18-0.15}$ & $12 * 18$ & $33.7 * 2.6$ & $\lambda=111$ & $\mathrm{~L}=1.22$ & $\lambda=104$ & $\mathrm{~L}=1.15$ & $\lambda=109$ & $\mathrm{~L}=1.20$ & $\lambda=94$ & $\mathrm{~L}=1.22$ \\
\hline $\mathrm{GL}_{18-0.30}$ & $12 * 18$ & $33.7 * 2.6$ & $\lambda=134$ & $\mathrm{~L}=1.45$ & $\lambda=123$ & $\mathrm{~L}=1.33$ & $\lambda=111$ & $\mathrm{~L}=1.20$ & $\lambda=10$ & $\mathrm{~L}=1.11$ \\
\hline
\end{tabular}

$\stackrel{\text { E }}{\mathrm{O}} \mathrm{I}$
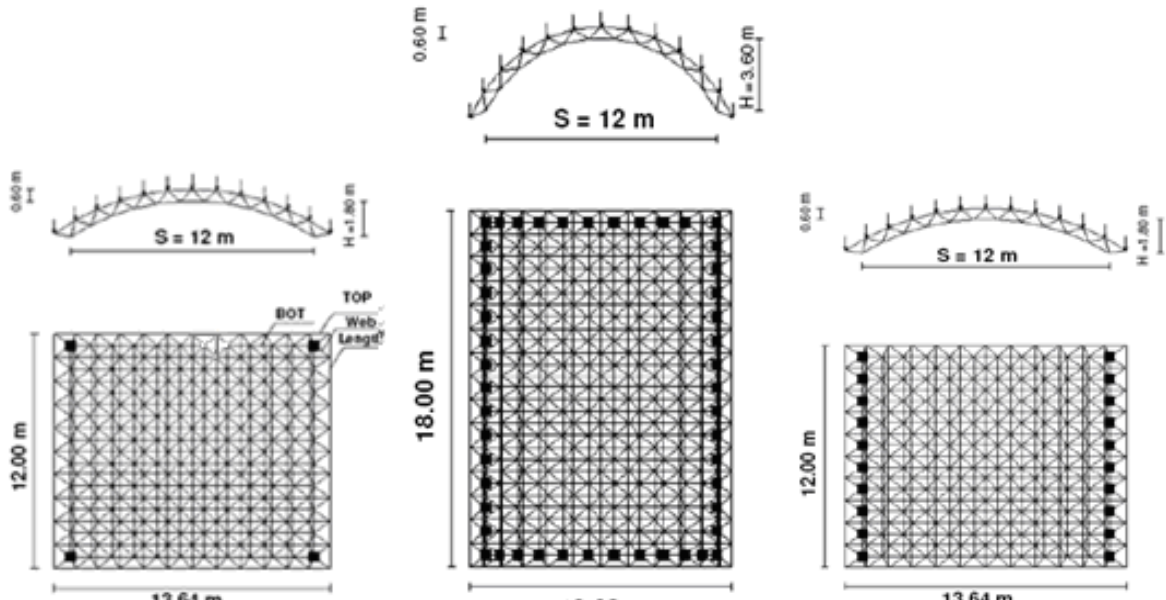

For Model GCl2-0.15

$13.62 \mathrm{~m}$

ForModel GE18-0.30

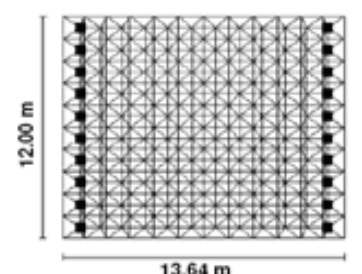

For Model GL12-0.15

Figure 1. Models configuration with different conditions.

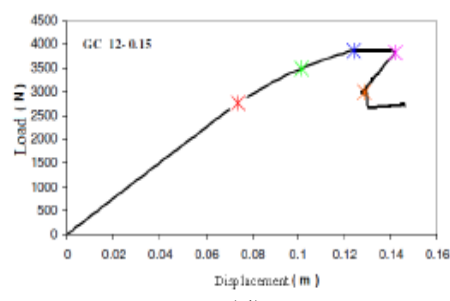

(a1)

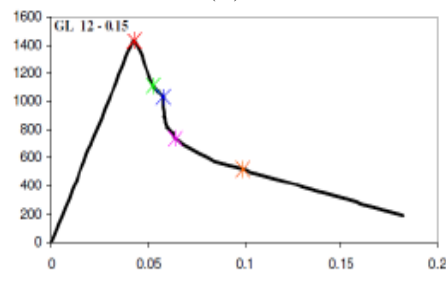

(c1)

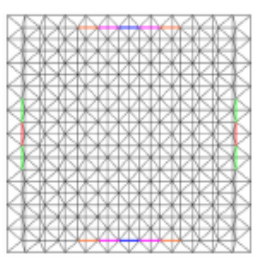

(a2)

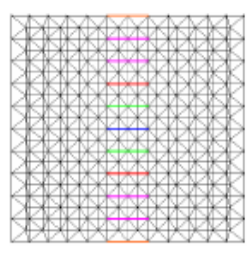

(c2)

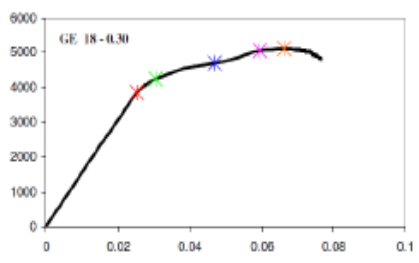

(b1)

The First set of collapse The second set of collapse The Third set of collapse The Fourth set of collapse The Fifth set of collapse

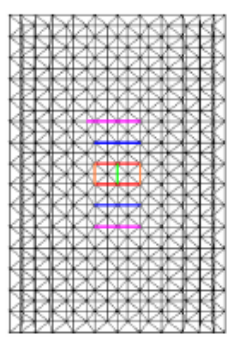

(b2)

Figure 2. Location and order of members collapse and load Static-displacement for sample. 
Table 2. Statical nonlinear analysis results.

\begin{tabular}{|c|c|c|c|c|c|}
\hline $\begin{array}{c}\text { Model } \\
\text { neam }\end{array}$ & $\begin{array}{c}\text { Primary load- } \\
\text { carying } \\
\text { capacity } \\
(\mathrm{N})\end{array}$ & $\begin{array}{c}\text { Final load } \\
\text { carying } \\
\text { capacity } \\
(\mathrm{N})\end{array}$ & $\begin{array}{c}\text { Primary } \\
\text { deflection } \\
(\mathrm{m})\end{array}$ & $\begin{array}{c}\text { Final } \\
\text { deflection } \\
(\mathrm{m})\end{array}$ & $\begin{array}{c}\mu=\text { Du/Dy } \\
\text { ductility } \\
\text { factor }\end{array}$ \\
\hline $\mathrm{GC}_{12-0.15}$ & 2760 & 3863 & 0.0738 & 0.1263 & 1.71 \\
\hline $\mathrm{GC}_{12-0.30}$ & 4288 & 4866 & 0.0944 & 0.1101 & 1.17 \\
\hline $\mathrm{GC}_{18-0.15}$ & 2563 & 4093 & 0.0894 & 0.2395 & 2.68 \\
\hline $\mathrm{GC}_{18-0.30}$ & 3528 & 4149 & 0.1125 & 0.1451 & 1.29 \\
\hline $\mathrm{GE}_{12-0.15}$ & 4686 & 4725 & 0.0262 & 0.0318 & 1.21 \\
\hline $\mathrm{GE}_{12-0.30}$ & 7308 & 8494 & 0.0200 & 0.0369 & 1.84 \\
\hline $\mathrm{GE}_{18-0.15}$ & 2658 & 2658 & 0.0377 & 0.0377 & 1.00 \\
\hline $\mathrm{GE}_{18-0.30}$ & 3859 & 5140 & 0.0252 & 0.0663 & 2.63 \\
\hline $\mathrm{GL}_{12-0.15}$ & 1435 & 1435 & 0.0427 & 0.0427 & $1 .$. \\
\hline $\mathrm{GL}_{12-0.30}$ & 1022 & 1032 & 0.0315 & 0.0382 & 1.22 \\
\hline $\mathrm{GL}_{18-0.15}$ & 1394 & 1394 & 0.0402 & 0.0402 & 1.00 \\
\hline $\mathrm{GL}_{18-0.30}$ & 1030 & 1030 & 0.0341 & 0.0341 & 1.00 \\
\hline
\end{tabular}

collapse starts from the most internal members and extension toward side members. At models with edge vertical-arch-supported, collapse starts from the most internal members of top layers of grid along are and extension toward side members.

3) Support conditions have an impress in collapse behaviour of double-layer space grids. According to Table 2 derived results show that with change of corner-supports to edge-supports and edge vertical-arch-supported, their ductility increases that its reason can be more load-carrying transmission which are prepared in edgesupports and edge vertical-arch-supported mode.

\section{Acknowledgements}

I Mahdi Darvish Hashemi of the Islamic Azad University and colleagues and other colleagues and friends who helped, especially the research to be published this research, I finally appreciated.

\section{References}

[1] Hanaor, A., Marsh, C. and Parke, G.A.R. (1989) Modification of Behaviour of Double-Layer Grids: Overview. J Struct Engng, ASCE, 115, 1021-1037. http://dx.doi.org/10.1061/(ASCE)0733-9445(1989)115:5(1021)

[2] El-Sheikh, A. (1998) Sensitivity of Space Trusses to Sudden Member Loss. Int J. of Space Structures, 12, 31-41.

[3] Sheidaii, M.R., Abedi, K. and Behravesh, A. (2001) Collapse Behaviour of Double Layer Space Trusses. Proceeding of the IASS Symposium on Theory Design and Realization of Shell and Spatial Structure, Nagoya. 